\title{
Satellite remote sensing to monitor mangrove forest resilience and resistance to sea level rise
}

Running Title: Monitoring mangrove sea level rise resilience

Clare Duncan $^{1,2,3^{*}}$, Harry J. F. Owen ${ }^{2}$, Julian R. Thompson ${ }^{3}$, Heather J. Koldewey ${ }^{4,5}$, Jurgenne H. Primavera $^{4,6}$, Nathalie Pettorelli ${ }^{2}$

${ }^{1}$ Centre for Integrative Ecology, School of Life and Environmental Sciences, Deakin University, Burwood, Victoria 3121, Australia

${ }^{2}$ Institute of Zoology, Zoological Society of London, Outer Circle, Regent's Park, London NW1 4RY, UK

${ }^{3}$ UCL Department of Geography, University College London, Gower Street, London WC1E 6BT, UK

${ }^{4}$ Conservation Programmes, Zoological Society of London, Outer Circle, Regent's Park, London NW1 4RY, UK

${ }^{5}$ Centre for Ecology and Conservation, University of Exeter, Penryn, Cornwall TR10 9EZ, UK

${ }^{6}$ Zoological Society of London-Philippines, 43-E Burgos Street, Barangay Magdalo, La Paz, 5000 Iloilo City, Philippines

*Corresponding author: clare.duncan@deakin.edu.au

Paper type: Standard paper

Word count: 7,583

Abstract: 262

Figures: 4

Tables: 7

\section{Tweetable abstract:}

A new satellite monitoring approach reveals spatial incongruence in coastal ecosystem vulnerability processes and drivers 


\section{ABSTRACT}

- Coastal ecosystems, such as mangroves, provide key ecosystem services for climate change mitigation and adaptation. However, combined anthropogenic activities and climatic change-driven sea level rise (SLR) pose a severe threat to their global persistence, and to the continued delivery of these services. Mangrove vulnerability to SLR depends upon capacity for both resilience (landward migration) and resistance (maintained functioning with the existing distribution), which are in turn hindered by extractive activities and coastal infrastructure development. Limited landscape-scale data availability means existing SLR vulnerability assessment frameworks lack rigorous quantification of these discrete processes.

- Here we develop and implement a novel multi-product (multispectral, microwave, derived-product) open-access satellite remote sensing approach to assess both coastal ecosystem SLR resilience and resistance capacity in multiple mangrove sites across the world, and landscape-level and anthropogenic factors driving these capacities. Our approach allows comparative ranking of resilience and resistance capacities across sites, based on relative changes in constraints to these two components of SLR vulnerability.

- We observe generally low SLR resilience and resistance across our case study sites. Interestingly, we find that site-specific resilience and resistance capacities and constraints can be highly incongruent, highlighting the importance of comprehensive SLR vulnerability monitoring for effective management. High within-site variation was also detected in resilience and resistance capacities and their constraints. This underlines the importance of spatially-explicit monitoring at extensive spatial scales to inform decision making.

- The methodology developed and repeat-pass imagery employed adds to the remote monitoring and assessment toolkit for adaptive coastal ecosystem management under SLR, providing a new approach to inform conservation and management priority assessments in data deficient regions. 


\section{INTRODUCTION}

Global sea level rise (SLR) presents a major threat to coastal ecosystems, and to the multiple ecosystem services they provide to humans (see de Groot et al. 2012; Brander et al. 2012). Management focus is increasingly placed on coastal zone risk assessment and mitigation, in order to enhance climate change mitigation and adaptation (CCMA). The potential future success of activities to enhance CCMA hinges on adaptive management under variable climatic projections (IPCC 2013) to reduce coastal ecosystem vulnerability to SLR. In order to plan for change, monitoring of the relative potential for coastal ecosystems to maintain functionality and service delivery in the face of SLR, and the factors principally driving their vulnerability, is required. Quantitative and semi-quantitative site-specific information on coastal ecosystem exposure, sensitivity and adaptive capacity to SLR (Lee et al. 2017; Ellison 2015) currently enable categorisation of these systems according to relative vulnerability. However, such assessments often do not comprehensively assess components of vulnerability to specific factors, are rarely fully spatially-explicit (but see Lee et al. 2017), and importantly do not allow for high temporal resolution monitoring of changes in the drivers inherently shaping spatial variation in vulnerability to SLR.

Owing to their often-extensive areal coverage, dense vegetation and deep, organic carbon-rich sediments, global mangrove forests provide arguably the greatest coastal zone ecosystem-specific CCMA potential (Dahdouh-Guebas et al. 2005; Donato et al. 2011; McIvor et al.2012). They are, however, highly sensitive to SLR impacts. Mangrove SLR resilience can be broken down in to two components, termed resilience (capacity for maintained areal coverage [e.g. through landward migration]) and resistance (capacity to maintain functionality within existing distributions [e.g. maintained productivity]; Gilman et al. 2008). This distinction is key, as the underlying processes (abiotic and anthropogenic pressures) affecting mangrove resilience and resistance capacities may vary (Gilman et al. 2008). Resistance is driven predominantly through sediment accretion and surface elevation gain (root biomass production) relative to SLR (sediment and freshwater inputs), and cryptic degradation with maintained areal coverage (e.g. selective cutting and pollution) (Dahdouh-Guebas et al. 2005; Lee et al. 2014; Lovelock et al. 2015). Sediment and freshwater input regimes may also impact mangrove SLR resilience (e.g. influencing levels of seaward die-back; 
51 Ellison 1993; Woodroffe 1995; Gilman et al. 2008; Ellison 2015). However, capacity for landward 52 migration is dependent principally on: (1) landward topography (hydro-ecological conditions for landward 53 recruitment); and (2) presence of landward physical barriers (anthropogenic structures: buildings; dikes; 54 sea walls; roads; agri-/aquaculture) (Gilman et al. 2008; Ellison 2015). Management to enhance mangrove 55 resilience and resistance thus necessitates different approaches. For example, resistance may benefit from 56 actions to increase sediment inputs and reduce cutting in stressed systems, while resilience may benefit 57 from actions to zone landward areas to facilitate landward expansion (Gilman et al. 2008; Rogers et al. 58 2014). Accordingly, to prioritise management to maximise coastal zone CCMA into the future where 59 resources and capacity are limited, combined examination of relative mangrove forest resilience and 60 resistance capacities is required.

61 Due largely to the complexities of mangrove field data collection, studies on SLR vulnerability to date have 62 often been limited in geographic scope (one or few forests: Ellison 1993; Gilman et al. 2007; Ellison \& 63 Zouh 2012), or have focussed on only one component of vulnerability in extensive regional assessments 64 (resistance: Lovelock et al. 2015; Sasmito et al. 2016). Where mangrove SLR resilience and resistance capacities have been assessed in parallel, anthropogenic controls on these processes (landward land-use change/development; cryptic degradation through cutting) have not been considered (Ellison \& Zouh 2012). Accordingly, we lack systematic, repeatable methods to index and monitor SLR resilience and resistance capacities across the large spatial scales required for decision-making, as well as methods to assess the predominant factors driving these under current anthropogenic activities and management regimes. Here, we develop and subsequently employ (global case study mangroves) a multi-product satellite remote sensing approach to simultaneously monitor mangrove SLR resilience and resistance capacities, and their potential abiotic and anthropogenic drivers. The approach allows ranking of resilience and resistance capacities across sites, while accounting for relative changes to constraints to these two components of SLR vulnerability, for management priority assessment. 


\section{Study sites}

Seven mangrove forests (West Africa to South Asia: Figure 1) were selected as case studies. Each site satisfied the following criteria: (1) large size (>5,000 ha; minimise influence from stochastic processes: Keith et al. 2013); (2) known and substantial historical SLR (5-15cm over 1993-2008; Beckley et al. 2010; GSFC 2013); (3) available satellite imagery (temporal coverage; comparable seasons) for all required products (Table S1). The sites are currently under varying levels of protection, ranging from no official protection to inclusion within protected areas, UNESCO World Heritage and Ramsar sites. All sustain extractive use, mostly at landward, upper-intertidal boundaries (e.g. timber extraction, land clearing: Diop et al. 2002; UNEP-WCMC 2003; 2007; Spalding et al. 2010), and experience varying amounts of human settlement/infrastructure and unconverted land at their landward boundaries.

\section{Satellite remote sensing data}

Multiple remote sensing data (multispectral and microwave) and products were employed to monitor: (1) mangrove resilience (areal maintenance; landward migration and/or shoreline retreat) and resistance (biomass maintenance within existing distribution) capacities; and (2) potential landscape-level (landward topographic slope and sediment availability) and anthropogenic development drivers (Table 1). Temporal coverages were limited to 2007-2010 (12.5m radar imagery availability; biomass change), 2007-2015 (matching recent multispectral imagery availability [2015 time of investigation] to assess longer-term changes at landward boundaries), and 2006-2010 (to assess trends in sediment availability around the timeperiod of radar imagery availability) (Table 1).

\section{Satellite data pre-processing}

All data processing was conducted in open-source software: R 3.2.5 (R Development Core Team 2016), QGIS 2.14.0 (QGIS Development Team 2016), ASF MapReady 3.1.24 (ASF 2013), and SENTINEL-1 Toolbox 4.0.0 (Array Systems Computing Inc. 2016). 
Six Landsat bands were used: blue, green, red, near infrared $[N I R]$, shortwave infrared $[S W I R] 1$ and 2. Atmospheric radiometric calibration and correction was applied via simple Dark Object Subtraction from the single darkest (minimum reflectance) band-specific pixel ('radCor'; 'sdos': Leutner \& Horning 2016). Adjacent scenes were mean mosaicked following band-specific histogram matching ('histMatch': Leutner \& Horning 2016), and resampled to ALOS/PALSAR imagery (bilinear interpolation). Vegetation, soil and water indices were calculated to improve the predictive ability of mangrove landcover classification

(Kuenzer et al. 2011; Lee et al. 2017): Normalised Difference Vegetation Index (NDVI); Enhanced Vegetation Index (EVI); Soil-Adjusted Vegetation Index (SAVI); Automated Water Extraction Index Index (NDWI); Normalised Multi-Band Drought Index (soil; $N M D I_{\text {soil }}$ ) (Table S4; Figure S4).

ALOS/PALSAR HV scenes were radiometrically calibrated to backscatter amplitude, co-registered and terrain-corrected (SRTM DEM) (ASF 2013). Automated image co-registration was applied between adjacent scenes ('coregisterImages': Leutner \& Horning 2016) for sites with $>1$ scene (Saloum Delta and Sundarbans; Figure 1) prior to mean mosaicking. Site-specific 2007 ALOS/PALSAR imagery was coregistered to $12.5 \mathrm{~m}$ Landsat-derived SAVI index (multi-product pixels' spatial alignment). Site-specific 2010 ALOS/PALSAR imagery was then co-registered to 2007 imagery (Cornforth et al. 2013). To reduce ALOS/PALSAR speckle noise (and maintain edge features: Lee et al. 1994) we used a two-dimensional discrete wavelet transformation: Maximal Overlap Discrete Wavelet Transform using Daubechies orthonormal compactly supported wavelet ( $L=8$; Daubechies 1992) ('denoise.modwt.2d': Whitcher 2015). Pixels >35m SRTM DEM within-canopy surface elevation are beyond the conditions in which mangrove forests grow (see Fatoyinbo et al. 2008). All pixels >35m SRTM DEM (resampled to 12.5m; bilinear interpolation) were therefore masked from further analyses (see also Lee et al. 2017). Pixels containing water bodies were masked on a threshold of $A W E I_{s h}>0$ (Feyisa et al. 2014; Li \& Gong 2016).

\section{Landcover classification}

The stepwise approach to quantifying current mangrove capacity for resilience and resistance is outlined in Figure 2. Low spectral complexity in coastal landcover facilitated unsupervised landcover classification 
(Wegmann et al. 2016). To determine potentially redundant variables (Landsat bands and indices; Table

S4; Figure S4) and improve site-specific multi-temporal classifications (Eklundh \& Singh 1993), unstandardized Principal Components Analyses (PCA; 'rasterPCA': Leutner \& Horning 2016) and PCA loadings inspections were conducted. The final set of input variables were then: red, NIR, SWIR $1, S W I R 2$, $A W E I_{\text {sh }}, M N D W I, N D W I, N D V I$ and $S A V I$. Unsupervised classification via kmeans clustering (HartiganWong), using 10,000 randomly-sampled pixels and 100 model iterations over 25 random starts, was conducted to cluster pixels into 10 classes (Wegmann et al. 2016; 'unsuperClass': Leutner \& Horning 2016). Site-specific unsupervised classifications were subsequently re-run with iterative removal of one class per interval, and assessed via visual inspection of meaningful classes (Giri 2016) against highresolution imagery (2006-2008 and 2014-2016 for each time-period: Google Earth 2016). Optimal number of classes for most sites was five, visually corresponding to mangrove, wet bare-ground (mudflats; aquaculture), dry bare-ground (sand; salt pans; pond banks; cleared [agriculture] and urban landcover), dry terrestrial forest and dry terrestrial shrub-/grass-/agricultural land. Further identified classes (>5) corresponded to: cloud, cloud shadow (Saloum Delta); multiple mangrove vegetation classes (top-dying disease [Sundarbans; Iftekhar \& Islam 2004]; shrubby, high saline mangroves [Mahajamba; Jones et al. 2015]).

To avoid eroding mangrove boundaries via post-classification filtering (Giri 2016; Wegmann et al. 2016), only larger, contiguous patches $\left(>3,600 \mathrm{~m}^{2}\right.$; four initial Landsat pixels) were considered in further analyses. To reduce mangrove change detection error from introduction of classification error at two time-periods and differences in Landsat sensor calibration (see Table S4), assessment of mangrove pixel-specific change was conducted (see Deng et al. 2008; Giri 2016). "Gain" or "loss" pixels in the 2015 mangrove distribution were conservatively maintained only if they also exhibited pixel-specific change in $N D V I \geq 25 \%$ from 2007 imagery.

Site-specific classification accuracies for identified mangrove distributions were conducted for 200 randomly-selected pixels per time-period (site areas with available high resolution optical imagery; Google Earth 2016). These pixels were polygonized for visual accuracy assessment into three categories to assess 
both true positives rates, and potential impact of mixed pixels on boundary extent and change classification (de Jong \& van der Meer 2007): (1) true mangrove (>50\% mangrove cover); (2) misclassified (0\% mangrove cover); (3) mixed pixel ( $\leq 50 \%$ mangrove cover) (Figure S5). Two hundred 'non-mangrove' (i.e. all other landcover classes) pixels per time-period were also randomly selected for visual accuracy assessment into three categories to assess true negative rates: (1) true 'non-mangrove' (0\% mangrove cover); (2) misclassified 'non-mangrove' ( $>50 \%$ mangrove cover); (3) mixed pixel.

\section{Mangrove boundary change 2007-2015 (resilience and resistance)}

Change in mangrove distribution 2007-2015 was assessed via spatial overlaying the two site-specific landcover classifications. Total area of gain and loss (ha) and percentage change were calculated as one index of capacity for landward resilience to SLR (Gilman et al. 2008) under current anthropogenic threats and management.

Change in seaward boundary 2007-2010 was assessed via ALOS/PALSAR HV backscatter amplitude change detection. Waterways display very low backscatter amplitude due to specular microwave reflection, and following from Cornforth et al. (2013) were determined and eliminated from further analyses using a threshold value on a $7 \times 7$ Refined Lee filter (Lee et al. 1994; edge variance threshold 5,000) on:

\section{$\sqrt{H V 2007+H V 2010}$}

where $H V=$ ALOS/PALSAR HV backscatter amplitude. This enabled extraction of pixels that were land in one year and water in the other, and thus identification of changes in coastline extent (Cornforth et al. 2013). All identified seaward mangrove pixels within five-pixels' distance (62.5m) from the 2007-2010 coastline edge were then analysed for significant biomass change (see next section). Site-specific comparison of coastline (biomass) and landward boundary (distribution shift) change was conducted as a second index of capacity for SLR resilience.

\section{Mangrove biomass change 2007-2010 (resistance)}


The capacity for biomass maintenance (resistance) was assessed via pixel-specific change detection in 197 pixel.

ALOS/PALSAR L-Band HV backscatter amplitude 2007-2010 (aboveground biomass proxy: Proisy et al. 2003; Lucas et al. 2014; Cornforth et al. 2013) within identified stable mangrove distributions. To produce conservative estimates (to reduce potential overestimation from any differences in tidal height at ALOS/PALSAR imagery acquisition times; see Cornforth et al. 2013), areas of $\geq 15 \%$ backscatter amplitude change were extracted: $10 \%$ change can correspond to a significant on-the-ground biomass change (Cornforth et al. 2013). Significant biomass changes which were detected are assumed herein to correspond to both SLR and anthropogenic processes. To index site-specific total significant biomass change, percentage significant change in the sum of total backscatter amplitude was calculated: from reference 2007 backscatter amplitude and + significant pixel-specific backscatter amplitude change (>15\%) in 2015 across all stable mangrove distribution pixels.

\section{Drivers of capacity for mangrove resilience and resistance}

\section{1: Topographic constraints to capacity for resilience}

All pixels immediately adjacent to site-specific 2007 landward mangrove boundaries were extracted (nine metre buffer [>pixel centre diagonal distance]) to create year 2007 mangrove landward perimeter pixel rasters. Seaward edge pixels were masked by $A W E I_{s h} 2007+A W E I_{s h} 2015>0$ (water in both years), and manual removal of seaward adjacent perimeter pixels not comprising water bodies (i.e. those behind mudflats, sandbanks, etc.) following polygonization. Year 2015 mangrove rasters were then cropped to the 2007 mangrove landward perimeter pixel polygons $(1=$ mangrove cover, or $0=$ no mangrove cover in 2015). Topographic slope (radians) of SRTM DEM elevation pixels (12.5m) was calculated (eight neighbours; 'terrain': Hijmans et al. 2016), and extracted for each 2007 mangrove landward perimeter

To assess within-site topographic controls on pixel-specific migration, an Integrated nested Laplace approximation (INLA) approach for latent Gaussian Markov random field models (Rue et al. 2009) was used to control for spatial structure (autocorrelation) in 2015 mangrove migration into 2007 mangrove 
landward perimeter pixels, using a Stochastic Partial Difference Equation (SPDE) (Lindgren et al. 2011;

Blangiardo et al. 2013). Site-specific binomial INLA SPDE models (Delauney triangulation mesh minimum observation distance $1.25 \mathrm{~km}$; maximum triangle edge 125,000 km) (Blangiardo \& Cameletti 2015; Lindgren \& Rue 2015) were employed using 20,000 randomly-sampled 2007 mangrove landward perimeter pixels and their associated SRTM DEM slope predictor variable (radians; square roottransformed). Site-specific topographic constraints to capacity for future landward migration was then indexed via the percentage of non-anthropogenic (see next section) 2007 landward perimeter pixels with SRTM DEM slope < the $95 \%$ quantile $(\theta)$ of the distribution of slope values for pixels with observed migration into the landward perimeter by 2015.

\section{2: Anthropogenic constraints to capacity for resilience and resistance}

To index potential site-specific anthropogenic constraints (i.e. infrastructure, cleared land [agriculture]) to landward migration (resilience) and biomass maintenance (resistance; pressure from extractive use), potential anthropogenic landcover was proxied by the number (length) and relative proportion of 2007 mangrove landward perimeter dry bare-ground pixels in both 2007 and 2015. To eliminate site-specific naturally-occurring (i.e. non-anthropogenic) dry bare-ground, proportional 'true' anthropogenic landcover was visually validated at each time-period via random-selection of 200 classified 2007 mangrove landward perimeter dry bare-ground pixels (>50\% pixel coverage: Google Earth 2016). The site-, time-period specific total number of identified 2007 mangrove landward perimeter potential anthropogenic (classified dry bare-ground) pixels were then scaled by validated proportional true anthropogenic cover.

\section{3: Sediment availability constraints to capacity for resilience and resistance}

Open-access eight-day composite Level 3 global TSM concentration $\left(\mathrm{g} \mathrm{m}^{-3}\right)$ data $(4 \mathrm{~km}$ resolution) were extracted from ACRI-ST (http://hermes.acri.fr/), and processed for pixel-specific mean TSM, and significant deseasoned trends (Mann Kendall tau value $p<0.05$, else tau $=0$ ) in TSM 2006-2010 ('significantTau': Detsch 2016). Extractive mangrove use is assumed to occur more frequently in more easily-accessible landward portions of forests. Thus, to index potential within-site sediment availability 
controls on the capacity for mangrove resilience and resistance (seaward boundary biomass change), all seaward mangrove pixels within five-pixels' distance $(62.5 \mathrm{~m})$ from the combined 2007-2010 coastline edge, and mean TSM and Kendall's tau of the closest TSM pixel ('gDistance': Bivand et al. 2016) were extracted. Site-specific single predictor and additive two-predictor Gaussian INLA SPDE models were constructed for 20,000 randomly-selected seaward mangrove pixels (percentage change ALOS/PALSAR HV backscatter amplitude 2007-2010). INLA SPDE models were assessed for significant effects via predictor-specific slope estimate 97.5\% quantiles, and compared via Deviance Information Criterion (DIC; Spiegelhalter et al. 2002) and Watanabe-Akaike Information Criterion (WAIC; Watanabe 2010) for Bayesian hierarchical models. Site-specific potential sediment availability constraints to capacity for future seaward boundary resilience and resistance were then indexed via the mean Kendall's tau value for all coastal TSM pixels with significant trends in TSM 2006-2010.

\section{Categorising resilience and resistance capacities, and severity of constraints}

Capacity for resilience was categorised based on the distribution of observed capacities as: high resilience (increasing/stable [ $<4 \%$ loss] area, and landward migration $>$ seaward biomass loss); medium resilience (stable $[<4 \%$ loss] area, and landward migration $\approx$ seaward biomass loss $[<2 \%$ seaward retreat $]$ ); low resilience (stable $[<4 \%$ loss]/decreasing area, and landward migration < seaward biomass loss). Capacity for resistance (total significant biomass change) was categorised as: high resistance (increasing/stable [ $<1 \%$ loss]); medium resistance (marginal [<5\%] loss); low resistance (> 5\% loss).

Site-specific constraints to the capacity for mangrove resilience and resistance were similarly ranked into categories of severity. Topographic constraints to the capacity for resilience (\% 2007 landward perimeter non-anthropogenic pixels with capacity for future migration [SRTM DEM slope $\leq \theta]$ ) were categorised as: low concern (>70\%); medium concern (50-70\%); high concern (<50\%). Anthropogenic development constraints to the capacity for resilience and resistance (\% change in landward perimeter pixels' anthropogenic landcover 2007-2015) were categorised as: low concern (decreasing/stable $[<0.5 \%$ increase]); medium concern (marginal increase [0.5-5\%]); high concern (>5\% increase). Sediment loss constraints to the capacity for resistance (mean Kendall's tau in TSM concentration $\left(\mathrm{g} \mathrm{m}^{-3}\right)$ 2006-2010) 
were categorised as: low concern (increasing/stable [>-0.01]); medium concern (marginal decrease [>-

\section{RESULTS}

Accuracy assessment of unsupervised landcover classifications at randomly selected classified mangrove pixels $(N=200$ per time-period [2007 and 2015] per site) revealed reasonable accuracy in mangrove landcover identification (means: true positives $=90.80 \%$; false positives $=3.89 \%$; 'mangrove' mixed pixels $259=6.00 \%$; true negatives $=90.32 \%$; false negatives $=5.54 \% ;$ 'non-mangrove' mixed pixels $=4.14 \% ;$ Table S5). Most sites showed increasing (Mahajamba, Save River Delta) or stable mangrove area over 20072015 (<2\% loss: Ruvuma Estuary, Rufiji Delta, Sundarbans, Saloum Delta; Table 2; Figure 3 and S6-S12).

Five of seven sites exhibited 2015 landward migration into the 2007 mangrove landward perimeter (Table

3). Net seaward significant biomass increase was observed at one site, where sediment availability (mean TSM $\mathrm{g} \mathrm{m}^{-3}$ ) was also high and stable: Mahajamba (3.13\%) (Tables 4 and 5). However, net seaward significant biomass loss $(-4.48 \%)$ was observed at the Sundarbans (Tables 4 and 5); but was outpaced by observed landward migration 2007-2015 (Table 3). Net seaward significant biomass loss was moderate in 267 the two West African sites, substantially outpacing landward migration at Saloum Delta (Tables 3 and 5). 268 Net seaward significant biomass loss was substantial in all East African sites (-5.54- -5.62\%), but was 269 outpaced by landward migration at Save River Delta and Ruvuma Estuary (Tables 3 and 5).

270 Mangrove aboveground biomass was stable or increasing at Mahajamba, Sundarbans and Sherbro Bay, 271 while marginal biomass loss $(<5 \%)$ was detected at Saloum Delta and Ruvuma Estuary (Table 6). 272 Substantial net significant biomass loss was observed at Save River Delta (-5.33\%) and Rufiji Delta ($2735.34 \%$ ) (Table 6), which was spatially heterogeneous and greater $(-6.05 \%)$ in the northern portion of the 274 Rufiji Delta where agricultural expansion was also observed (Figure 3).

275 Pixel-specific probability of 2015 landward migration was significantly negatively related to SRTM DEMderived slope (radians; square root-transformed) at all sites with observed landward migration 2007-2015 
( $b$ 97.5\% quantiles $<0$ ): greater landward migration probability with shallower topographic slope. The strongest negative effect was observed at Mahajamba $(b \sqrt{\text { SRTM slope }}=-2.30 \pm 0.25$ [1 s.d.]; $97.5 \%$

quantiles: $-2.80--1.81)$, and the weakest at Rufiji Delta $(b \sqrt{S R T M \text { slope }}=-0.66 \pm 0.28$ [1 s.d.]; $97.5 \%$ quantiles: $-1.21--0.16)$.

Most mangroves showed low site-specific topographic constraints to capacity for future landward migration; however, Sherbro Bay showed medium (63.07\% non-anthropogenic landward perimeter pixels slope $<\theta$ ), and Rufiji Delta exhibited high concern capacity (45.33\%) (Figure 4). These sites also exhibited medium to low resilience capacity, respectively, over 2007-2015.

Excepting Saloum Delta, an increase in landward perimeter potential anthropogenic landcover was observed at all sites (Table 7). The largest of these increases were observed in Sherbro Bay (medium concern: $3.09 \%$ perimeter increase) and Rufiji Delta (high concern: 6.34\% perimeter increase) (Table 7). and seaward boundary resilience: no significant mean Kendall's tau in TSM across all pixels at Save River

297 Delta and Ruvuma Estuary; a weak positive trend at Sherbro Bay ( $\operatorname{tau}=0.006)$; weak negative trends at 298 Mahajamba and Sundarbans ( $\operatorname{tau}=-0.005$ and -0.004 , respectively). Stronger negative trends in TSM were 299 found at Saloum Delta (tau $=-0.02$; medium concern), and Rufiji Delta (tau $=-0.04$; high concern) (Table 300 4; Figure 4). 
Based on our analyses, two sites showed high capacity for both resilience and resistance: Mahajamba and

302 Sundarbans (Figure 4). Both sites also showed low concern for all potential constraints to current and future 303 resilience and resistance. Two further sites had high resilience capacity, but had medium (Ruvuma Estuary) 304 to low (Save River Delta) resistance capacity, despite low concern for all proxied constraints (Figure 4).

305 Increases in landward perimeter anthropogenic landcover were observed in both sites (Table 7); however, 306 biomass loss at the low-elevation Save River Delta (Table 4) may be more associated with SLR impacts on 307 forest functionality, where observed anthropogenic development at landward boundaries was 308 comparatively marginal. Sherbro Bay showed stable biomass but medium resilience capacity, where low 309 concern was observed for changes to sediment availability, but medium concern observed for landward 310 topographic and anthropogenic barrier constraints to landward migration (Figure 4). Sites with lower 311 capacities for both resilience and resistance (Saloum Delta, Rufiji Delta) also had observed reductions in 312 sediment availability 2006-2010 (Figure 4). Low resilience and resistance capacity was observed at Rufiji 313 Delta, alongside high concern for all topographic, anthropogenic and sediment availability constraints to 314 future landward migration and biomass maintenance (Figure 4).

\section{DISCUSSION}

317 This study demonstrates the capability of multi-product satellite monitoring to simultaneously index 318 multiple elements of coastal ecosystem SLR vulnerability, and spatially-explicit landscape-level and 319 anthropogenic constraints (and trends therein). The main novelty of our approach is its ability to separately 320 monitor processes and drivers of SLR resilience and resistance across large spatial extents $(>5,000$ ha 321 forests). Our results show that: (1) incongruence can exist between site-specific resilience and resistance 322 capacities, and their probable predominant constraints, revealing the importance of comprehensive SLR 323 vulnerability monitoring; (2) there can be high within-site variation in both resilience and resistance 324 capacities, and in constraints to these processes (i.e. topographic; sediment availability), which necessitate spatially-explicit monitoring at these scales to inform decision-making. Our systematic monitoring 
approach can inform management prioritisation of higher risk elements of potential responses to SLR and 327 of actions to mitigate current and future constraints.

328 Our results clearly demonstrate that, given room for expansion (Gilman et al. 2008; Rogers et al. 2014), 329 mangroves can colonise landward along suitably shallow topographic gradients at fairly rapid rates (Table 3; Figure 4). Furthermore, where sediment loads are sufficiently high they can also extend seaward over the same timescales despite SLR (Table 5; Figure 4). Thus, although a less empirically-explored component of vulnerability (but see Gilman et al. 2007; Ellison \& Zouh 2012; Runting et al. 2016), resilience can provide an important contribution to SLR adaptability where constraints to expansion are low. Our findings do, however, urge caution against resilience assessment via areal coverage alone, as reduced productivity and extractive degradation may cause cryptic loss of functionality (also low resistance) at ecosystem boundaries (Figures 3 and 4). Biomass loss is both a consequence and driver of SLR vulnerability: as biomass is lost, capacity for sediment trapping and surface elevation gain also decreases (McKee et al. 2007). Satellite monitoring (SAR) of these processes provides a key tool to inform necessary management. However, at present, our approach can monitor only capacity for resistance processes (under existing pressures and management), and not directly attribute observed biomass changes with specific SLR impacts. Much previous mangrove SLR vulnerability research has focussed on resistance: predominantly on relative surface elevation gain via Rod-Surface Elevation Tables (R-SETs) (i.e. Lovelock et al. 2015). Conversely to satellite-derived information, the global R-SET network is limited (Sasmito et al. 2016) and unable to capture ecosystem-wide variation in resistance. It may also under-/overestimate vulnerability where capacity for boundary changes are not considered. Going forward, a key development will lie in linking SAR-derived vegetation structure change with field-derived sediment elevation capital information (see Lovelock et al. 2015) to improve remote SLR resistance monitoring. et al. 2015): we find both high resilience and resistance capacities in only two sites (also all topographic, anthropogenic and sediment availability constraints low concern), with most others showing incongruent capacities. Only one site had low resilience and resistance capacities (all constraints high concern: Rufiji 
Delta; Figure 4). Overall, lower SLR resilience and resistance capacities were observed in mainland African mangroves. Resilience capacities were a concern for West Africa, coinciding with topographic, anthropogenic (Sherbro Bay) and decreasing sediment availability constraints to landward migration (Saloum Delta; Figure 4). Zoning to reduce future anthropogenic development in shallow-sloping landward areas and catchment management to maximise freshwater and sediment inputs (regional desertification: see Saenger \& Bellan 1995; Ndour et al. 2011) may be important considerations for enhancing the resilience of West African coastal ecosystems. Low resistance capacities, and seaward boundary resilience, were conversely a concern for East Africa, largely coinciding with landward anthropogenic development constraints (Figures 3 and 4: cryptic degradation; but see Save River Delta: Results; Figure 4). Minimisation of unsustainable extractive activities near population centres, and agricultural and infrastructural development within existing mangrove boundaries, as well as in potential migration areas, should be a regional priority for East Africa to enhance SLR resistance into the future (Gilman et al. 2008). The spatial configuration of landward anthropogenic pressures may have significance in determining the intensity of impact upon mangrove forest SLR resilience and resistance capacities (see Figure 3), and is a key area for future development. The case studies considered represent ecosystems with low comparative anthropogenic pressure. Capacity for SLR resistance, and particularly resilience, in the wider tropics (c.f. Southeast Asia) is likely to be substantially lower, where extensive anthropogenic pressure exists at landward margins (Lovelock et al. 2015; Richards \& Friess 2016), as well as in low sediment-fed small islands (Sasmito et al. 2016). Geographically rolling-out the framework developed in this study will in future facilitate a more comprehensive view of global mangrove SLR resilience and resistance capacities.

372 Our developed monitoring approach is not without limitation. First, we were unable to control for timeperiod-specific tidal height differences in ALOS/PALSAR imagery; thus, while we employed conservative thresholds $(\geq 15 \%)$ for 'significant' on-ground biomass change (see Materials and Methods; Cornforth et al. 2014), changes to below-canopy standing water may have influenced resistance capacities' quantification in more open-canopy sites. Employment of recently-launched, much-increased temporal coverage Sentinel-1 SAR satellite data (Copernicus 2016; but see short-wavelength C-band limitation: see 
Lucas et al. 2014) may enable imagery tidal-matching in future applications. Second, to minimise the impacts of cross-sensor (Landsat) spectral differences, we applied an NDVI threshold for 'true' mangrove distribution change. This, alongside 30m Landsat imagery resolution (minimum mapping unit for isolated patches then four pixels) and 'scaling-up' to ALOS/PALSAR resolution (12.5m), means our approach is currently conservative in its quantification of SLR resilience capacities, being less able to detect fine-scale landward migration - i.e. common-place gradual movement of sparse individuals (see Kelleway et al. 2016). Multi-sensor fusion with higher resolution optical imagery (e.g. Cavanaugh et al. 2014), where available, could enhance resilience capacities' quantification. Third, SRTM DEM represents withincanopy, not true ground, elevation (Fatoyinbo et al. 2008); thus, overestimation of landward topographic slopes is risked due to inclusion of mangrove and non-mangrove SRTM pixels. Going forward, masking by emerging global mangrove height models (i.e. Fatoyinbo et al. 2016) will assist in minimising this limitation. Finally, at present our approach does not consider site-specific stochastic climatic extremes (i.e. storms; Lee et al. 2017). Storm impacts may influence SLR resilience and resistance capacities, and their quantification herein, via periodic reduction of mangrove productivity and landward establishment. Indeed, cyclone Bondo hit Mahajamba in October 2007 ( $~ 70$ knots; $~ 8$ months pre-ALOS/PALSAR imagery acquisition: Kossin et al. 2010); biomass recovery from which may have contributed in part to estimated high resistance capacity (Table 6; Figures 4 and S6.10). Pre- (cyclone Favio; February 2007) and withininvestigation period storms (Sidr: November 2007; Rashimi: October 2008) were also experienced at Save

River Delta and Sundarbans, respectively (Kossin et al. 2010). Further research into the potential for storm impacts (frequency, intensity) to limit coastal ecosystem SLR resilience and resistance capacities is now required to extend our approach for their inclusion.

In summary, we have integrated multiple satellite data and products to present a new spatially-explicit approach to more comprehensive monitoring of SLR resilience and resistance capacities, which minimises 401 costly, time-intensive and logistically challenging on-ground monitoring requirements. While we have 402 focussed application of our SLR vulnerability monitoring approach to mangroves, it is applicable to all 
404 [salt]marshes; freshwater/peat swamps). Potentially lower sensitivities of SAR backscatter to biomass and 405 change detection in low-/open-canopy marsh (but see Ramsey et al. 2014) may, however, necessitate 406 substitution/fusion with multispectral-derived productivity proxies (e.g. NDVI; Table S4). Extension of our 407 approach to sub-tropical and temperate regions will further require inclusion of metrics on climatic extreme 408 (temperature) controls on SLR resilience and resistance capacities (encroachment and productivity: see e.g. 409 Cavanaugh et al. 2014). The global and repeat-pass coverage of optical (Landsat) and SAR sensors 410 (ALOS/PALSAR and PALSAR-2), and novel increased temporal coverage satellites (Sentinel-1 C-Band 411 SAR and -2 multispectral: Copernicus 2016), could facilitate repeated, near real-time monitoring of 412 resilience and resistance capacities, SLR responses, and their drivers using and developing upon the 413 approach developed herein into the future. This can inform adaptive management of coastal ecosystems in 414 the face of rising sea levels. Minor adaptation of our multi-product approach to monitoring differential 415 threat processes and responses within ecosystem cores and at boundaries could, moreover, provide useful 416 inputs into wider marine and terrestrial ecosystem risk assessment procedures (i.e. Lee et al. 2017; Keith et 417 al. 2013), and the evaluation of conservation measures (i.e. protected area effectiveness: Joppa et al. 2008;

418 Pettorelli et al. 2012). 


\section{ACKNOWLEDGEMENTS}

ALOS/PALSAR imagery access was granted by the European Space Agency under ESA Science Projects 17441 and 23529. C.D. was supported by a UCL BEAMS Impact award, and further acknowledges funding support from the Darwin Initiative. We are grateful to Calvin Lee for analytical assistance, and to Mark Huxham and Emily Lines for advice on an earlier version of this manuscript.

\section{AUTHOR CONTRIBUTIONS}

C.D. and N.P. conceived the ideas; C.D. designed the methodology; C.D. collected and analysed the data; H.J.F.O. assisted in conducting remote sensing analyses; C.D. led the writing of the manuscript, and N.P., H.J.F.O, J.R.T., H.J.K. and J.H.P. contributed critically to the drafts and gave final approval for publication. 


\section{REFERENCES}

Array Systems Computing Inc. (2016). SENTINEL-1 Toolbox version 4.0.0. Available at: http://step.esa.int/main/download/. (Accessed 22nd August 2016).

ASF (Alaska Satellite Facility) (2013). MapReady vesion 3.1.24. Available at: https://www.asf.alaska.edu/data-tools/mapready/. (Accessed 10th October 2013).

ASF DAAC (Alaska Satellite Facility NASA Distributed Active Archive Centre) (2016). Vertex. Available at: https://vertex.daac.asf.alaska.edu/. (Accessed 25th July 2016).

Beckley, B.D., Zelensky, N.P., Holmes, S.A., Lemoine, F.G., Ray, R.D., et al. (2010). Assessment of the Jason-2 extension to the TOPEX/Poseidon, Jason-1 Sea-Surface Height Time Series for global mean sea level monitoring. Marine Geodesy, 33, 447-471.

Bivand, R., Rundel, C., Pebesma, E., Hufthammer, K.O. (2016). rgeos: Interface to Geometry Engine Open Source (GEOS). R Package version 0.3-19. Available at: https://cran.rproject.org/web/packages/rgeos/index.html.

Blangiardo, M., Cameletti, M. (2015). Spatial and Spatio-temporal Bayesian Models with R-INLA. John Wiley \& Sons, Chichester, UK.

Blangiardo, M., Cameletti, M., Baio, G., Rue, H. (2013). Spatial and spatio-temporal models with R-INLA. Spatial and Spatio-temporal Epidemiology, 7, 39-55.

Brander, L.M., Wagtendonk, A.J., Hussain, S.S., McVittie, A., Verburg, P.H., de Groot, R.S., van der Ploeg, S. (2012). Ecosystem service values for mangroves in South East Asia: A meta-analysis and value transfer application. Ecosystem Services, 1, 62-69.

Cavanaugh, K.C., Kellner, J.R., Forde, A.J., Gruner, D.S., Parker, J.D., Rodriguez, W., Feller, I.C. (2014). Poleward expansion of mangrove is a threshold response to decreased frequency of extreme cold events. Proceedings of the National Academy of Sciences USA, 111, 723-727.

Copernicus (2016). Sentinel 1-A data. Available at: https://scihub.copernicus.eu/dhus/.

Cornforth, W.A., Fatoyinbo, T.E., Freemantle, T.P., Pettorelli, N. (2013). Advanced Land Observing Satellite Phased Array Type L-Band SAR (ALOS PALSAR) to inform the conservation of mangroves: Sundarbans as a case study. Remote Sensing, 5, 224-237.

Dahdouh-Guebas, F., Jayatissa, L.P., Di Nitto, D., Bosire, J.O., Lo Seen, D., Koedam, N. (2005). How effective were mangroves as a defence against the recent tsunami? Current Biology, 15, 443-447.

Daubechies, I. (1992). Ten Lectures on Wavelets. Volume 61 of CBMS-NSF Regional Conference Series in Applied Mathematics. Society for Industrial and Applied Mathematics, Philadelphia.

de Groot, R.S., Brander, L., van der Ploeg, S., Costanza, R., Bernard, F., et al. (2012). Global estimates of the value of ecosystems and their services in monetary units. Ecosystem Services, 1, 50-61.

de Jong, S.M., van der Meer, F.D. (2007). Remote Sensing Image Analysis: Including the Spatial Domain. Volume 5 of Remote Sensing and Digital Image Processing. Springer Science \& Business Media, Berlin, Germany. 
Deng, J.S., Wang, K., Deng, Y.H., Qi, G.J. (2008). PCA-based land-use change detection and analysis using multitemporal and multisensory satellite data. International Journal of Remote Sensing, 29, 48234838.

Detsch, F. (2016). gimms: Download and Process GIMMS NDVI3g Data. Package version 0.5.1. Available at: https://cran.r-project.org/web/packages/gimms/index.html.

Diop, E.S., Gordon, C., Semesi, A.K., Soumaré, A., Diallo, N., et al. (2002). Mangroves of Africa. In: Mangrove Ecosystems: Function and Management (Lacerda, L.D. ed.). pp. 63-121. Springer, Berlin.

Donato, D.C., Kauffman, J.B., Murdiyarso, D., Kurniato, S., Stidham, S., Kannien, M. (2011). Mangroves among the most carbon-rich forests in the tropics. Nature Geoscience, 4, 293-297.

Eklundh, L., Singh, A. (1993). A comparative analysis of standardised and unstandardized Principal Components Analysis in remote sensing. International Journal of Remote Sensing, 14, 1359-1370.

Ellison, J.C. (1993). Mangrove retreat with rising sea-level, Bermuda. Estuarine and Coastal Shelf Science, $37,75-87$.

Ellison, J.C. (2015). Vulnerability assessment of mangroves to climate change and sea-level rise impacts. Wetlands Ecology and Management, 23, 115-137.

Ellison, J.C., Zouh, I. (2012). Vulnerability to climate change of mangroves: assessment from Cameroon, Central Africa. Biology, 1, 617-638.

ESA (European Space Agency) (2013). EOLi-SA. Available at: https://earth.esa.int/web/guest/eoli. (Accessed 10th October 2013).

ESA GLOBCOLOUR (2014). MERIS Total Suspended Matter 2014. Accessed through ACRI-ST 29th July 2016.

Fatoyinbo, T.E., Lagomasino, D., Lee, S.K., Simard, M., Feliciano, E., Trettin, C. (2016). High-resolution 3-dimensional mapping of forest structure and aboveground biomass stocks in blue carbon ecosystems in the Americas, Africa and South Asia. Proceedings of the $4^{\text {th }}$ Mangrove and Macrobenthos Meeting, St. Augustine, Florida, USA.

Fatoyinbo, T.E., Simard, M., Washington-Allen, R.A., Shugart, H.H. (2008). Landscape-scale extent, height, biomass and carbon estimation of Mozambique's mangrove forests with Landsat ETM+ and Shuttle Radar Topography Mission elevation data. Journal of Geophysical Research, 113, G02-S06.

Feyisa, G.L., Meilby, H., Fensholt, R., Proud, S.R. (2014). Automated Water Extraction Index: A new technique for surface water mapping using Landsat imagery. Remote Sensing of Environment, 140, 23-35.

Gilman, E.L., Ellison, J., Coleman, R. (2007). Assessment of mangrove response to projected relative sealevel rise and recent historical reconstruction of shoreline position. Environmental Monitoring and Assessment, 124, 105-130.

Gilman, E.L., Ellison, J., Duke, N.C., Field, C. (2008). Threats to mangroves from climate change and adaptation options: a review. Aquatic Botany, 237-250.

Giri, C. (2016). Remote Sensing of Land Use and Land Cover: Principles and Applications. Remote Sensing Applications Series. CRC Press, Boca Raton, USA. 
Google Earth (2016). Google Earth v. 7.1.5.1557. Google, Mountain View, California, USA. Available at: www.google.com/earth. (Accessed 20th June 2016).

GSFC (NASA Goddard Space Flight Centre) (2013). Integrated Multi-Mission Ocean Altimeter Data for Climate Research complete time series Version 2. PO.DAAC, California. Available at: http://dx.doi.org/10.5067/ALTTS-TJ122. (Accessed 26th October 2015).

Hijmans, R.J., van Etten, J., Cheng, J., Mattiuzzi, M., Sumner, M., et al. (2016). raster: Geographic Data Analysis and Modeling. $\mathrm{R}$ Package version 2.5-8. Available at: https://cran.rproject.org/web/packages/raster/index.html.

Iftekhar, M.S., Islam, M.R. (2004). Degeneration of Bangladesh's Sundarbans mangroves: A management issue. International Forestry Review, 6, 123-135.

IPCC (Intergovernmental Panel on Climate Change). (2013). Climate Change 2013: The Physical Science Basis. Contribution of Working Group I to the Fifth Assessment Report of the Intergovernmental Panel on Climate Change (Stocker, T.F., Qin, G.-K., Plattner, M., Tignor, M., Allen, S.K., Boschung, J., Nauels, A., Xia, Y., Bex, V., Midgley, P.M. eds.). Cambridge University Press, Cambridge.

JAXA/METI (Japanese Aerospace Exploration Agency/Ministry of the Economy, Trade and Industry) (2009). ALOS PALSAR L1.5 2009. Accessed through ASF DAAC 25th July 2016.

JAXA/METI (2010). ALOS PALSAR L1.5 2010. Accessed through ESA 10th October 2013.

Jones, T.G., Ratsimba, H.R., Ravaoarinorotsihoarana, L., Glass, L., Benson, L., et al. (2015). The dynamics, ecological variability and estimated carbon stocks of mangroves in Mahajamba Bay, Madagascar. Journal of Marine Science and Engineering, 3, 793-820.

Joppa, L.N., Loarie, S.R., Pimm, S.L. (2008). On the protection of "protected areas". Proceedings of the National Academy of Sciences, 105, 6673-6678.

Kelleway, J.J., Saintilan, N., Macreadie, P.I., Skilbeck, C.G., Zawadzki, A., Ralph, P.J. (2016). Seventy years of continuous encroachment substantially increases 'blue carbon' capacity as mangroves replace intertidal salt marshes. Global Change Biology, 22, 1097-1109.

Kossin, P., Kruk, M., Schreck, C. (2010). NCDC International Best Track Archive for Climate Stewardship (IBTrACS) Project, Version 3. NOAA National Center for Environmental Information. DOI: 10.7289/V5NK3BZP. Available at: www.ncdc.noaa.gov/ibtracs/; www.coast.noaa.gov/hurricanes/. (Accessed 20 $0^{\text {th }}$ September 2017).

Kuenzer, C., Bluemel, A., Gebhardt, S., Quoc, T.V., Dech, S. (2011). Remote sensing of mangrove ecosystems: A review. Remote Sensing, 3, 878-928.

Lee, J.S., Jurkevich, L., Dewaele, R., Wambacq, P., Oosterlinck, A. (1994). Speckle filtering of synthetic aperture radar images: A review. Remote Sensing Reviews, 8, 311-340.

Lee, S.Y., Primavera, J.H., Dahdouh-Guebas, F., McKee, K., Bosire, J.O., et al. (2014). Ecological role and services of tropical mangrove ecosystems: A reassessment. Global Ecology and Biogeography, 23, 726-743.

Lee, C.K.F., Duncan, C., Owen, H.J.F., Pettorelli, N. (2017). A new framework to assess relative ecosystem vulnerability to climate change. Conservation Letters, early online view. 
Keith, D.A., Rodríguez, J.P., Rodríguez-Clark, K.M., Nicholson, E., Aapala, K., et al. (2013). Scientific foundations for an IUCN Red List of Ecosystems. PLoS ONE, 8, e62111.

Leutner, B., Horning, N. (2016). RStoolbox: Tools for Remote Sensing Data Analysis. R Package version 0.1.4. Available at: https://cran.r-project.org/web/packages/RStoolbox/index.html.

Li, W., Gong, P. (2016). Continuous monitoring of coastline dynamics in western Florida with a 30-year time series of Landsat imagery. Remote Sensing of Environment, 179, 196-209.

Lindgren, F., Rue, H. (2015). Bayesian spatial modelling with R-INLA. Journal of Statistical Software, 63, $1-25$.

Lindgren, F., Rue, H., Lindström, J. (2011). An explicit link between Gaussian fields and Gaussian Markov random fields: the stochastic partial differential equation approach. Journal of the Royal Statistical Society B - Statistical Methodology, 73, 423-498.

Lovelock, C.E., Cahoon, D.R., Friess, D.A., Guntenspergen, G.R., Krauss, K.W., et al. (2015). The vulnerability of Indo-Pacific mangrove forests to sea-level rise. Nature, 526, 559-563.

Lucas, R.M., Rebelo, L.-M., Fatoyinbo, L., Rosenqvist, A., Itoh, T., et al. (2014). Contribution of L-band SAR to systematic global mangrove monitoring. Marine and Freshwater Research, 65, 589-603.

McIvor, A.L., Möller, I., Spencer, T., Spalding, M. (2012). Reduction of wind and swell waves by mangroves. Natural Coastal Protection Series: Report 1. Cambridge Coastal Research Unit Working Paper 40. Nature Conservancy and Wetlands International, Cambridge.

McKee, K.L., Cahoon, D.R., Feller, I.C. (2007). Caribbean mangroves adjust to rising sea level through biotic controls on change in soil elevation. Global Ecology and Biogeography, 16, 545-556.

Pettorelli, N., Chauvenet, A.L.M., Duffy, J.P., Cornforth, W.A., Meillere, A., Baillie, J.E.M. (2012). Tracking the effect of climate change on ecosystem functioning using protected areas: Africa as a case study. Ecological Indicators, 20, 269-276.

Proisy, C., Mitchell, A., Lucas, R., Fromard, F., Mougin, E. (2003). Estimation of mangrove biomass using multifrequency radar data. Application to mangroves of French Guiana and Northern Australia. Proceedings of the Mangrove 2003 Conference, Salvador, Bahia, Brazil, 20-24 May 2003.

QGIS Development Team (2016). QGIS Geographic Information System version 2.14.0. Open Source Geospatial Foundation Project. Available at: http://www.qgis.org/.

R Development Core Team (2016). R: A Language and Environment for Statistical Computing. Version 3.2.5. R Foundation for Statistical Computing, Vienna.

Rahman, A.F., Dragoni, D., El-Masri, B. (2011). Response of the Sundarbans coastline to sea level rise and decreased sediment flow: a remote sensing assessment. Remote Sensing of Environment, 115, 3121-3128.

Rahman, M., Islam, K. (2010). The causes of deterioration of Sundarban mangrove forest ecosystem of Bangladesh: conservation and sustainable management issues. AACL Bioflux, 3, 77-90.

Ramsey, E. III, Rangoonwala, A., Chi, Z., Jones, C.E., Bannister, T. (2014). Marsh Dieback, loss and recovery mapped with satellite optical, airborne polarimetric radar, and field data. Remote Sensing of Environment, 152, 364-374. 
Rogers, K., Saintilan, N., Copeland, C. (2014). Managed retreat of saline coastal wetlands: Challenges and opportunities identified from the Hunter River Estuary, Australia. Estuaries and Coasts, 37, 67-78.

Rue, H., Martino, S., Chopin, N. (2009). Approximate Bayesian inference for latent Gaussian models by using integrated nested Laplace approximations. Journal of the Royal Statistical Society B - Statistical Methodology, 71,1-35.

Saenger, P., Bellan, M.F. (1995). The mangrove vegetation of the Atlantic Coast of Africa: a review. Université de Toulouse, Toulouse, France.

Sasmito, S.D., Murdiyarso, D., Friess, D.A., Kurianto, S. (2016). Can mangroves keep pace with contemporary sea level rise? A global data review. Wetlands Ecology and Management, 24, 263-278.

Spegelhalter, D.J., Best, N.G., Carlin, B.P., Van Der Linde, A. (2002). Bayseian measures of model complexity and fit. Journal of the Royal Statistical Society B - Statistical Methodology, 64, 583-639.

Spalding, M., Kainuma, M., Collins, L. (2010). World Atlas of Mangroves. Earthscan, London, UK.

UNEP-WCMC (UNEP, World Conservation Monitoring Centre) (2003). Mangroves of East Africa. UNEPWCMC, Cambridge.

UNEP-WCMC (2007). Mangroves of Western and Central Africa. UNEP Regional Seas Programme, UNEP-WCMC, Cambridge.

USGS (United States Geological Survey) (2014). Shuttle Radar Topography Mission (SRTM) 1 ArcSecond Global. Global Land Cover Facility, University of Maryland, Maryland.

USGS (2015). Earth Explorer. Available at: http://earthexplorer.usgs.gov/. (Accessed 15th October 2015).

Watanabe, S. (2010). Asymptotic equivalence of Bayes cross validation and widely applicable information criterion in singular learning theory. Journal of Machine Learning Research, 11, 3571-3594.

Wegmann, M., Leutner, B., Dech, S. (2016). Remote Sensing and GIS for Ecologists: Using Open Source Software. Pelagic Publishing, Exeter, UK.

Whitcher, B. (2015). waveslim: Basic wavelet routines for one-, two- and three-dimensional signal processing. $\mathrm{R}$ Package version 1.7.5. Available at: https://cran.r-project.org/web/packages/ waveslim/index.html.

Woodroffe, C.D. (1995). Response of tide-dominated mangrove shorelines in Northern Australia to anticipated sea-level rise. Earth Surface Processes and Landforms, 20, 65-85. 
TABLES

Table 1. Satellite remote sensing data and products employed.

\begin{tabular}{|c|c|c|c|c|}
\hline Data & Parameter(s) & $\begin{array}{l}\text { Spatial } \\
\text { resolution }\end{array}$ & $\begin{array}{l}\text { Temporal } \\
\text { coverage }\end{array}$ & References \\
\hline $\begin{array}{l}\text { Landsat } 5 \text { TM and } \\
8 \text { OLI/TIRS } \\
\text { (multispectral) }\end{array}$ & $\begin{array}{l}\text { - Areas of stable mangrove } \\
\text { distribution } \\
\text { - Landward migration } \\
\text { - Landward margins } \\
\text { anthropogenic landcover }\end{array}$ & $30 \mathrm{~m}$ & $\begin{array}{l}2007-2015 \\
\text { (but see } \\
\text { Table S2) }\end{array}$ & USGS 2015 \\
\hline $\begin{array}{l}\text { ALOS/PALSAR } \\
\text { L-Band HV } \\
\text { polarisation } \\
\text { Synthetic } \\
\text { Aperture Radar } \\
\text { (SAR) (Level } 1.5 \\
\text { processed; } \\
\text { amplitude) }\end{array}$ & $\begin{array}{l}\text { - Biomass changes } \\
\text { - Seaward boundary } \\
\text { biomass changes }\end{array}$ & $12.5 \mathrm{~m}$ & $\begin{array}{l}2007-2010 \\
\text { (but see } \\
\text { Table S3) }\end{array}$ & $\begin{array}{l}\text { JAXA/METI 2009; } 2010 \\
\text { ASF DAAC } 2016 \\
\text { ESA } 2013 \\
\text { Proisy et al. } 2003 \\
\text { Lucas } \text { et al. } 2014 \\
\text { Cornforth } \text { et al. } 2013\end{array}$ \\
\hline $\begin{array}{l}\text { SRTM Digital } \\
\text { Elevation Model } \\
(\mathrm{DEM} ; \mathrm{m})\end{array}$ & $\begin{array}{l}\text { - Landward topographic } \\
\text { slopes }\end{array}$ & $30 \mathrm{~m}$ & $\begin{array}{l}2000 \\
\text { (single } \\
\text { date) }\end{array}$ & USGS 2014 \\
\hline $\begin{array}{l}\text { Eight-day } \\
\text { composite } \\
\text { ENVISAT- } \\
\text { MERIS Total } \\
\text { Suspended Matter } \\
\left(\mathrm{TSM} ; \mathrm{g} \mathrm{m}^{-3}\right)\end{array}$ & $\begin{array}{l}\text { - Mean sediment } \\
\text { availabilities } \\
\text { - Temporal trends in } \\
\text { sediment availability }\end{array}$ & $4 \mathrm{~km}$ & 2006-2010 & $\begin{array}{l}\text { ESA GLOBCOLOUR } \\
2014 \\
\text { Lovelock et al. } 2015\end{array}$ \\
\hline
\end{tabular}


Table 2. Results of mangrove distribution change assessments (spatial overlays of mangrove landcover classifications 2007-2015).

\begin{tabular}{lccccccc}
\cline { 2 - 7 } Site & $\mathbf{2 0 0 7}$ (ha) & $\mathbf{2 0 1 5}$ (ha) & Loss (ha) & Gain (ha) & $\begin{array}{c}\text { Stable } \\
\text { (ha) }\end{array}$ & $\begin{array}{c}\text { Change } \\
\text { (ha) }\end{array}$ & $\begin{array}{c}\text { Change } \\
(\%)\end{array}$ \\
\hline $\begin{array}{l}\text { Saloum } \\
\text { Delta, SN }\end{array}$ & $472,177.40$ & $471,728.80$ & 644.48 & 195.92 & $471,532.90$ & -448.60 & -0.09 \\
\hline $\begin{array}{l}\text { Sherbro Bay, } \\
\text { SL }\end{array}$ & $196,085.30$ & $191,262.80$ & $4,831.97$ & 10.80 & $191,252.00$ & $-4,822.50$ & -2.46 \\
\hline $\begin{array}{l}\text { Save River } \\
\text { Delta, MZ }\end{array}$ & $60,182.05$ & $62,919.28$ & 483.27 & $3,220.5$ & $59,698.78$ & 2.737 .23 & 4.55 \\
\hline $\begin{array}{l}\text { Ruvuma } \\
\text { Estuary, TZ }\end{array}$ & $13,700.62$ & $13,787.84$ & 37.14 & 124.36 & $13,663.48$ & 87.22 & 0.64 \\
\hline $\begin{array}{l}\text { Rufiji Delta, } \\
\text { TZ }\end{array}$ & $43,000.92$ & $43,157.88$ & 651.69 & 808.64 & $42,349.23$ & 156.96 & 0.36 \\
\hline $\begin{array}{l}\text { Mahajamba, } \\
\text { MG }\end{array}$ & $71,953.86$ & $80,650.56$ & $1,784.50$ & $10,481.20$ & $70,169.36$ & $8,696.70$ & 12.09 \\
\hline $\begin{array}{l}\text { Sundarbans, } \\
\text { IN \& BD }\end{array}$ & $638,198.60$ & $639,528.40$ & 82.25 & $1,411.98$ & $638,116.40$ & $1,329.80$ & 0.21 \\
\hline
\end{tabular}


Table 3. Results of mangrove landward migration assessment 2007-2015 (into one-pixel wide 2007 mangrove landward perimeters: Materials and Methods).

\begin{tabular}{lccc}
\cline { 2 - 4 } Site & $\begin{array}{c}\text { Total landward pixels } \\
\text { (No. \& length; km) }\end{array}$ & $\begin{array}{c}\text { Landward pixels } \\
\text { migrated 2007-2015 } \\
\text { (No. \& length; km) }\end{array}$ & $\begin{array}{c}\text { Proportion landward } \\
\text { pixels migrated } \\
\text { 2007-2015 (\%) }\end{array}$ \\
\hline Saloum Delta, SN & $6,192,415$ & 0 & 0.00 \\
\hline Sherbro Bay, SL & $77,405.19$ & 0.00 & 0.00 \\
\hline Save River Delta, MZ & 701,606 & 0 & 20.98 \\
\hline Ruvuma Estuary, TZ & $8,770.08$ & 0.00 & 6.53 \\
\hline Rufiji Delta, TZ & 380,151 & 79,768 & 1.85 \\
\hline Mahajamba, MG & $4,751.89$ & 997.10 & 31.11 \\
\hline Sundarbans, IN \& BD & 49,225 & 3,215 & \\
\hline
\end{tabular}


Table 4. Summary of SRTM DEM-derived landward topographic and ENVISAT MERIS-derived total suspended matter (TSM; $\mathrm{g} \mathrm{m}^{-3}$ ) data at each study site. Figures in bold represent significant mean Kendall's tau TSM $\left(\mathrm{g} \mathrm{m}^{-3}\right)$ trend estimates based on bootstrapped $95 \%$ confidence intervals (CIs).

\begin{tabular}{|c|c|c|c|c|}
\hline Site & $\begin{array}{c}\text { Mean elevation } \\
(\mathrm{m} \text {; range })\end{array}$ & $\begin{array}{c}\text { Mean slope } \\
\text { (radians; range) }\end{array}$ & $\begin{array}{c}\text { Mean TSM } \\
\left(\mathrm{g} \mathrm{m}^{-3} ; 95 \% \text { CIs; }\right. \\
\text { range })\end{array}$ & $\begin{array}{c}\text { Mean } \\
\text { Kendall's tau } \\
\text { TSM } \\
\text { (95\% CIs; range) }\end{array}$ \\
\hline $\begin{array}{l}\text { Saloum Delta, } \\
\text { SN }\end{array}$ & $\begin{array}{c}12.86 \\
(0.00-34.99)\end{array}$ & $\begin{array}{c}0.04 \\
(0.00-0.94)\end{array}$ & $\begin{array}{c}10.41 \\
(10.01-10.80 ; \\
0.03-37.84)\end{array}$ & $\begin{array}{c}\mathbf{- 0 . 0 2} \\
(-0.02--0.01 \\
-0.40-0.26)\end{array}$ \\
\hline $\begin{array}{l}\text { Sherbro Bay, } \\
\text { SL }\end{array}$ & $\begin{array}{c}11.57 \\
(0.00-34.99)\end{array}$ & $\begin{array}{c}0.05 \\
(0.00-0.74)\end{array}$ & $\begin{array}{c}5.32 \\
(4.93-5.69 \\
0.04-21.28)\end{array}$ & $\begin{array}{c}\mathbf{0 . 0 0 6} \\
(0.003-0.008 ; \\
-0.09-0.28) \\
\end{array}$ \\
\hline $\begin{array}{l}\text { Save River } \\
\text { Delta, } \\
\text { MZ }\end{array}$ & $\begin{array}{c}4.84 \\
(0.00-27.02)\end{array}$ & $\begin{array}{c}0.003 \\
(0.00-0.45)\end{array}$ & $\begin{array}{c}9.92 \\
(9.07-10.77 ; \\
0.12-19.66) \\
\end{array}$ & $\begin{array}{c}0.001 \\
(-0.001-0.003 ; \\
-0.08-0.09) \\
\end{array}$ \\
\hline $\begin{array}{l}\text { Ruvuma } \\
\text { Estuary, } \\
\text { TZ } \\
\end{array}$ & $\begin{array}{c}11.72 \\
(0.00-34.99)\end{array}$ & $\begin{array}{c}0.04 \\
(0.00-0.51)\end{array}$ & $\begin{array}{c}5.77 \\
(3.93-7.42 ; \\
0.12-17.47)\end{array}$ & $\begin{array}{c}-0.01 \\
(-0.02-0.004 \\
-0.21-0.00) \\
\end{array}$ \\
\hline $\begin{array}{l}\text { Rufiji Delta, } \\
\text { TZ }\end{array}$ & $\begin{array}{c}12.17 \\
(0.00-34.99)\end{array}$ & $\begin{array}{c}0.04 \\
(0.00-0.69)\end{array}$ & $\begin{array}{c}9.69 \\
(7.70-11.59 ; \\
1.00-27.39)\end{array}$ & $\begin{array}{c}\mathbf{- 0 . 0 4} \\
(-0.05--0.02 \\
-0.21-0.02)\end{array}$ \\
\hline $\begin{array}{l}\text { Mahajamba, } \\
\text { MG }\end{array}$ & $\begin{array}{c}14.55 \\
(0.00-34.99)\end{array}$ & $\begin{array}{c}0.04 \\
(0.00-0.79)\end{array}$ & $\begin{array}{c}13.08 \\
(11.70-14.45 \\
0.20-34.88)\end{array}$ & $\begin{array}{c}\mathbf{- 0 . 0 0 5} \\
(-0.009--0.001 ; \\
-0.25-0.12)\end{array}$ \\
\hline $\begin{array}{l}\text { Sundarbans, } \\
\text { IN \& BD }\end{array}$ & $\begin{array}{c}6.27 \\
(0.00-34.93)\end{array}$ & $\begin{array}{c}0.03 \\
(0.00-0.61)\end{array}$ & $\begin{array}{c}20.90 \\
(20.40-21.40 ; \\
1.05-32.55)\end{array}$ & $\begin{array}{c}\mathbf{- 0 . 0 0 4} \\
(-0.007--0.002 ; \\
-0.18-0.20)\end{array}$ \\
\hline
\end{tabular}


Table 5. Results of ALOS/PALSAR HV backscatter amplitude seaward boundary change detections (fivepixels' distance of combined 2007-2010 coastline edges) 2007-2010. Significantly increasing/decreasing pixels are indexed as those with $\geq 15 \% \mathrm{HV}$ backscatter amplitude change (see Materials and Methods).

\begin{tabular}{|c|c|c|c|c|c|c|}
\hline Site & $\begin{array}{c}\text { Coverage } \\
\text { of total } \\
\text { stable } \\
\text { mangrove } \\
\text { area } \\
(\text { ha; \%) }\end{array}$ & $\begin{array}{c}\text { Seaward } \\
\text { significantly } \\
\text { increasing } \\
\text { (ha) }\end{array}$ & $\begin{array}{c}\text { Seaward } \\
\text { significantly } \\
\text { decreasing } \\
\text { (ha) }\end{array}$ & $\begin{array}{c}\text { Seaward } \\
\text { significantly } \\
\text { increasing } \\
(\%)\end{array}$ & $\begin{array}{c}\text { Seaward } \\
\text { significantly } \\
\text { decreasing } \\
(\%)\end{array}$ & $\begin{array}{c}2007-2010 \\
\text { total } \\
\text { significant } \\
\text { seaward } \\
\text { biomass } \\
\text { change }(\%)\end{array}$ \\
\hline Saloum, SN & $\begin{array}{c}54,285.45 \\
11.51\end{array}$ & $1,454.02$ & 755.14 & 38.24 & 19.86 & -2.81 \\
\hline Sherbro, SL & $\begin{array}{c}51,600.06 \\
26.98\end{array}$ & 432.08 & 506.00 & 23.06 & 27.00 & -0.60 \\
\hline Save, MZ & $\begin{array}{c}31,617.58 \\
52.96\end{array}$ & 290.30 & 520.67 & 20.11 & 36.06 & -5.54 \\
\hline Ruvuma, TZ & $\begin{array}{c}13,591.00 \\
99.45\end{array}$ & 175.77 & 332.23 & 19.14 & 36.18 & -5.57 \\
\hline Rufiji, TZ & $\begin{array}{c}34,710.97 \\
81.96\end{array}$ & 200.83 & 415.39 & 16.72 & 34.59 & -5.62 \\
\hline $\begin{array}{l}\text { Mahajamba, } \\
\text { MG }\end{array}$ & $\begin{array}{c}19,987.47 \\
28.48 \\
\end{array}$ & 272.70 & 167.97 & 39.62 & 24.40 & 3.13 \\
\hline $\begin{array}{l}\text { Sundarbans, } \\
\text { IN \& BD }\end{array}$ & $\begin{array}{c}216,747.30 \\
33.97\end{array}$ & 286.89 & 597.63 & 16.93 & 35.26 & -4.48 \\
\hline
\end{tabular}


Table 6. Results of ALOS/PALSAR HV backscatter amplitude change detections (constant mangrove distribution) over 2007-2010. Significantly increasing/decreasing pixels are indexed as those with $\geq 15 \%$ HV backscatter amplitude change (see Materials and Methods).

\begin{tabular}{|c|c|c|c|c|c|c|}
\hline Site & $\begin{array}{c}\text { Coverage } \\
\text { of total } \\
\text { stable } \\
\text { mangrove } \\
\text { area } \\
(\text { ha; \%) }\end{array}$ & $\begin{array}{c}\text { Signif. } \\
\text { increasing } \\
\text { (ha) }\end{array}$ & $\begin{array}{c}\text { Signif. } \\
\text { decreasing } \\
\text { (ha) }\end{array}$ & $\begin{array}{c}\text { Signif. } \\
\text { increasing } \\
(\%)\end{array}$ & $\begin{array}{c}\text { Signif. } \\
\text { decreasing } \\
(\%)\end{array}$ & $\begin{array}{c}2007-2010 \\
\text { total } \\
\text { significant } \\
\text { biomass } \\
\text { change } \\
(\%)\end{array}$ \\
\hline $\begin{array}{l}\text { Saloum } \\
\text { Delta, SN }\end{array}$ & $\begin{array}{c}54,285.45 \\
11.51\end{array}$ & $11,313.03$ & $13,985.12$ & 20.84 & 25.76 & -2.04 \\
\hline $\begin{array}{l}\text { Sherbro Bay, } \\
\text { SL }\end{array}$ & $\begin{array}{c}51,600.06 \\
26.98\end{array}$ & $11,532.41$ & $12,142.22$ & 22.35 & 23.53 & -0.62 \\
\hline $\begin{array}{l}\text { Save River } \\
\text { Delta, MZ }\end{array}$ & $\begin{array}{c}31,617.58 \\
52.96\end{array}$ & $5,860.44$ & $11,159.64$ & 18.54 & 35.30 & -5.33 \\
\hline $\begin{array}{l}\text { Ruvuma } \\
\text { Estuary, TZ }\end{array}$ & $\begin{array}{c}13,591.00 \\
99.45\end{array}$ & $2,546.23$ & $4,257.66$ & 18.73 & 31.33 & -3.96 \\
\hline $\begin{array}{l}\text { Rufiji Delta, } \\
\text { TZ }\end{array}$ & $\begin{array}{c}34,710.97 \\
81.96 \\
\end{array}$ & $5,269.42$ & $11,705.89$ & 15.18 & 33.72 & -5.34 \\
\hline $\begin{array}{l}\text { Mahajamba, } \\
\text { MG }\end{array}$ & $\begin{array}{c}19,987.47 \\
28.48\end{array}$ & $5,712.23$ & $4,302.40$ & 28.58 & 21.53 & 1.56 \\
\hline $\begin{array}{l}\text { Sundarbans, } \\
\text { IN \& BD }\end{array}$ & $\begin{array}{c}216,747.30 \\
33.97\end{array}$ & $37,263.08$ & $40,356.98$ & 17.19 & 18.62 & -0.66 \\
\hline
\end{tabular}


Table 7. Results of landward anthropogenic development analyses. Anthropogenic landward pixels = validated anthropogenic dry bare-ground landcover within one-pixel wide year 2007 mangrove landward perimeters in years 2007 and 2015. Numbers in brackets represent proportional 'true' validated anthropogenic landcover from total classified mangrove landward perimeter dry bare-ground pixels used to scale anthropogenic landward pixel numbers $(N=200$ pixels; see Materials and Methods).

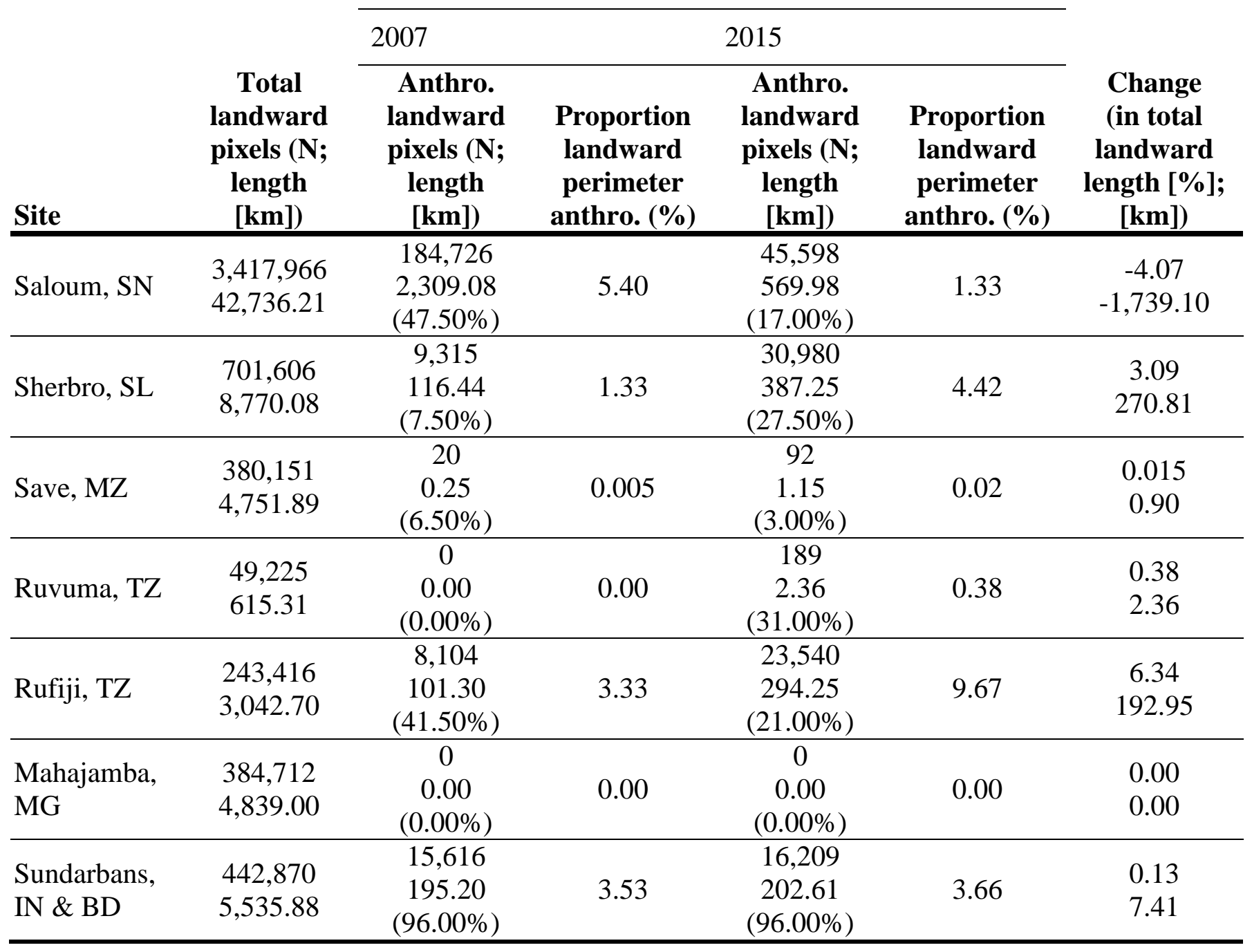




\section{FIGURE LEGENDS}

Figure 1. Mangrove study sites from West Africa to South Asia. Displayed imagery: Landsat 5 TM and 8 OLI/TIRS imagery (USGS 2015). (a) Saloum Delta, Senegal; (b) Sherbro Bay, Sierra Leone; (c) Save River Delta, Mozambique; (d) Ruvuma Estuary, Tanzania; (e) Rufiji Delta, Tanzania; (f) Mahajamba, Madagascar; (g) Sundarbans, India and Bangladesh. See also Table S1.

Figure 2. Schematic of the multi-product remote sensing approach to index mangrove SLR resilience and resistance capacity. PCA = principal components analysis. Red arrows: processing stages for resilience capacity; green arrows: processing stages for resistance capacity.

Figure 3. Distribution, biomass and seaward boundary change assessment at Rufiji Delta, Tanzania. a) spatial overlay of distribution change 2007-2015; b) close-up of the northern delta, with heavy mangrove clearing for agriculture observed (mid-dark grey in underlaid 2015 Landsat imagery); c) ALOS/PALSAR L-Band HV backscatter amplitude change detection 2007-2010 within the stable 2007-2015 mangrove distribution (pixel-specific significant biomass change $=\geq 15 \%$ change); significant biomass change northern delta $=-6.05 \%$, southern delta $=-4.56 \%$; d) [for visualisation only] resampled significant biomass change in seaward mangrove boundary pixels $2007-2010$ (62.5m resolution).

Figure 4. Ranking of identified current mangrove resilience and resistance capacities for management prioritisation. $\mathrm{L}=$ landward; $\mathrm{S}=$ seaward; migration ability = percentage of current (2015) non-dry bareground (c.f. potential anthropogenic) landcover with suitable topographic slope for landward migration $(\leq$ $\theta$ [95\% quantile SRTM DEM slope of migrated pixels]); potential change (resilience) $=$ percentage increase in potential anthropogenic development 2007-2015; potential change (resistance) $=$ mean trend in sediment availability (mean Kendall's tau ENVISAT MERIS-derived TSM [g $\left.\mathrm{m}^{-3}\right]$ 2006-2010; ESA GLOBCOLOUR 2014). Rankings: red = low; orange = medium; green $=$ high . 


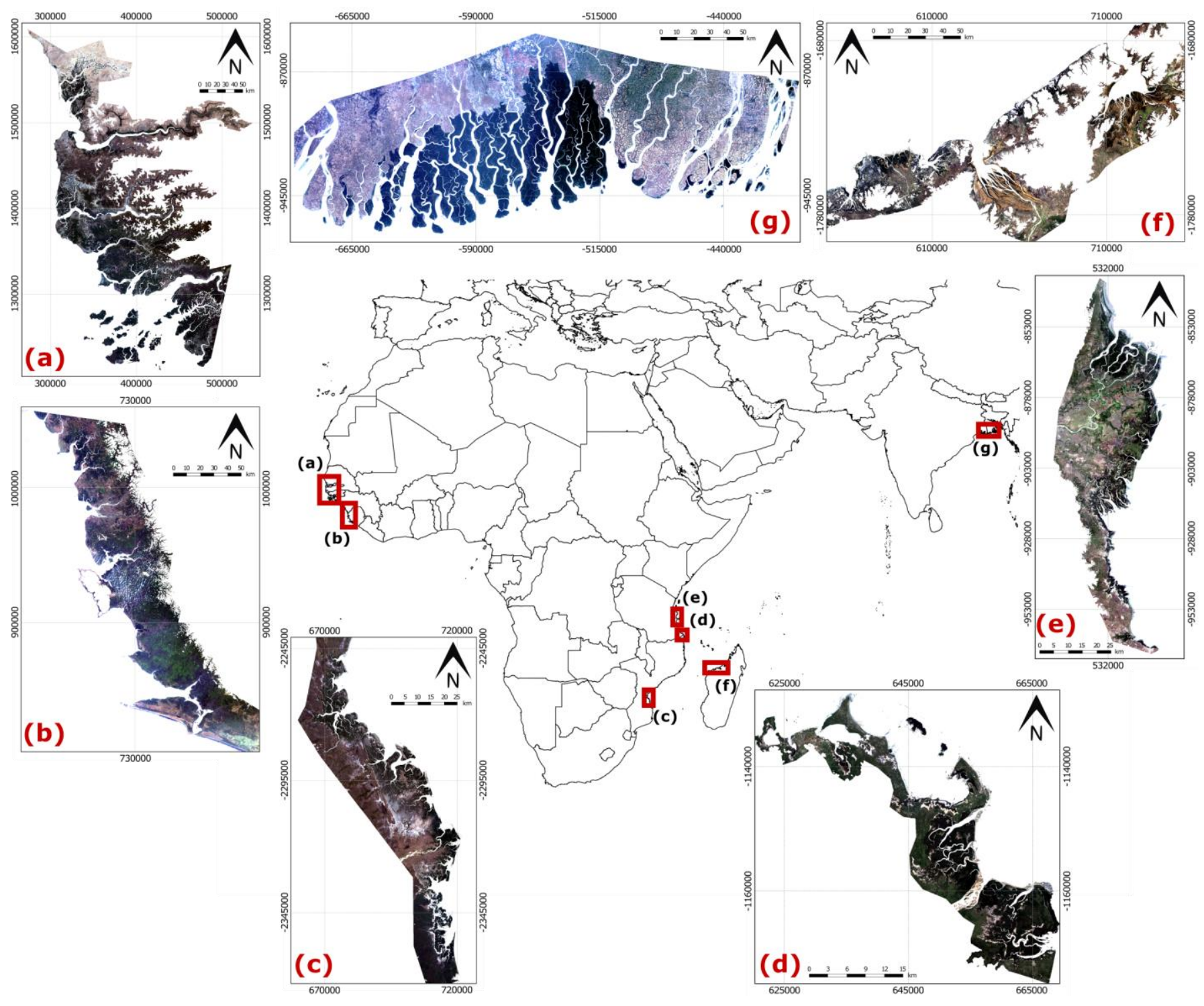




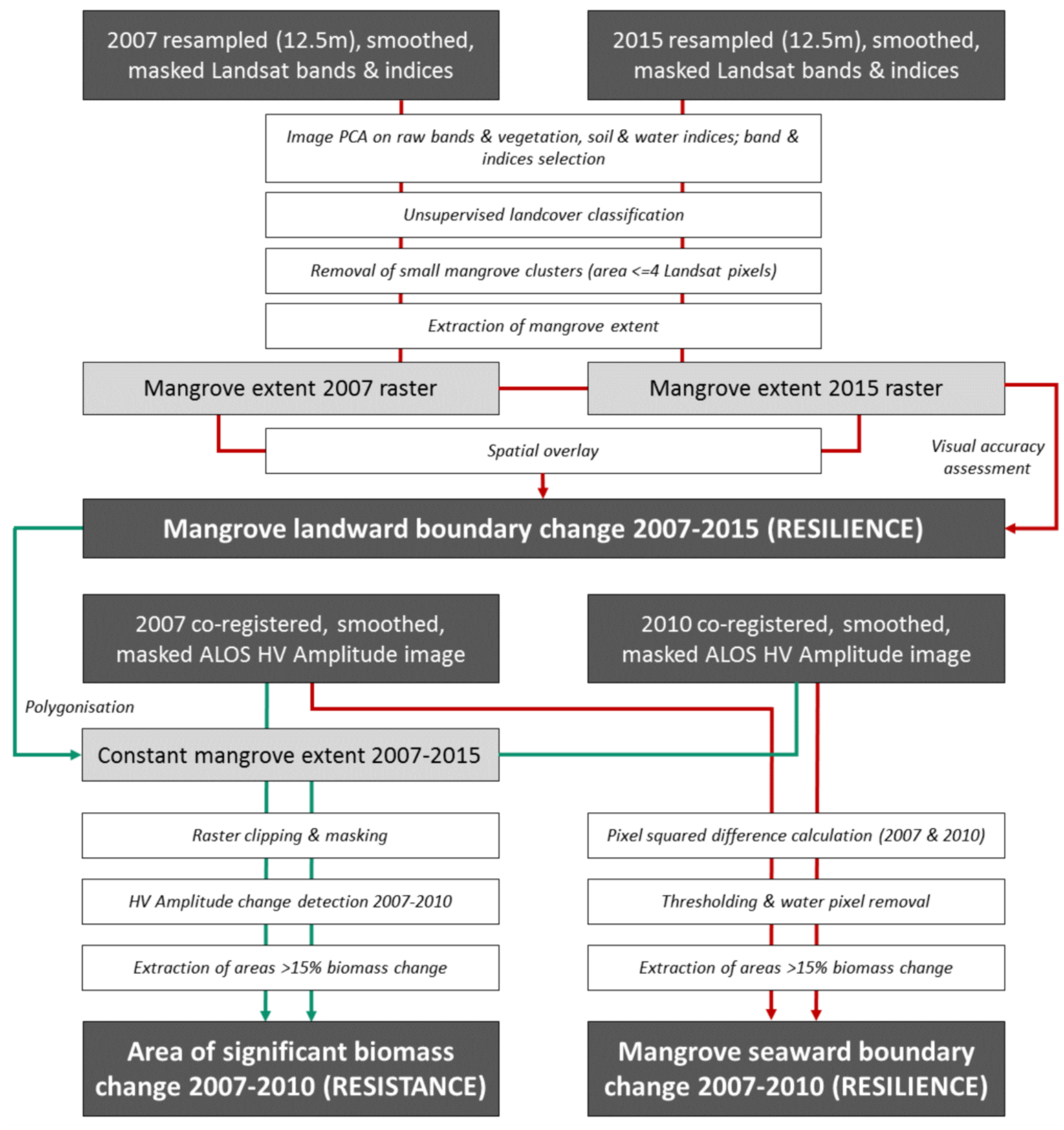



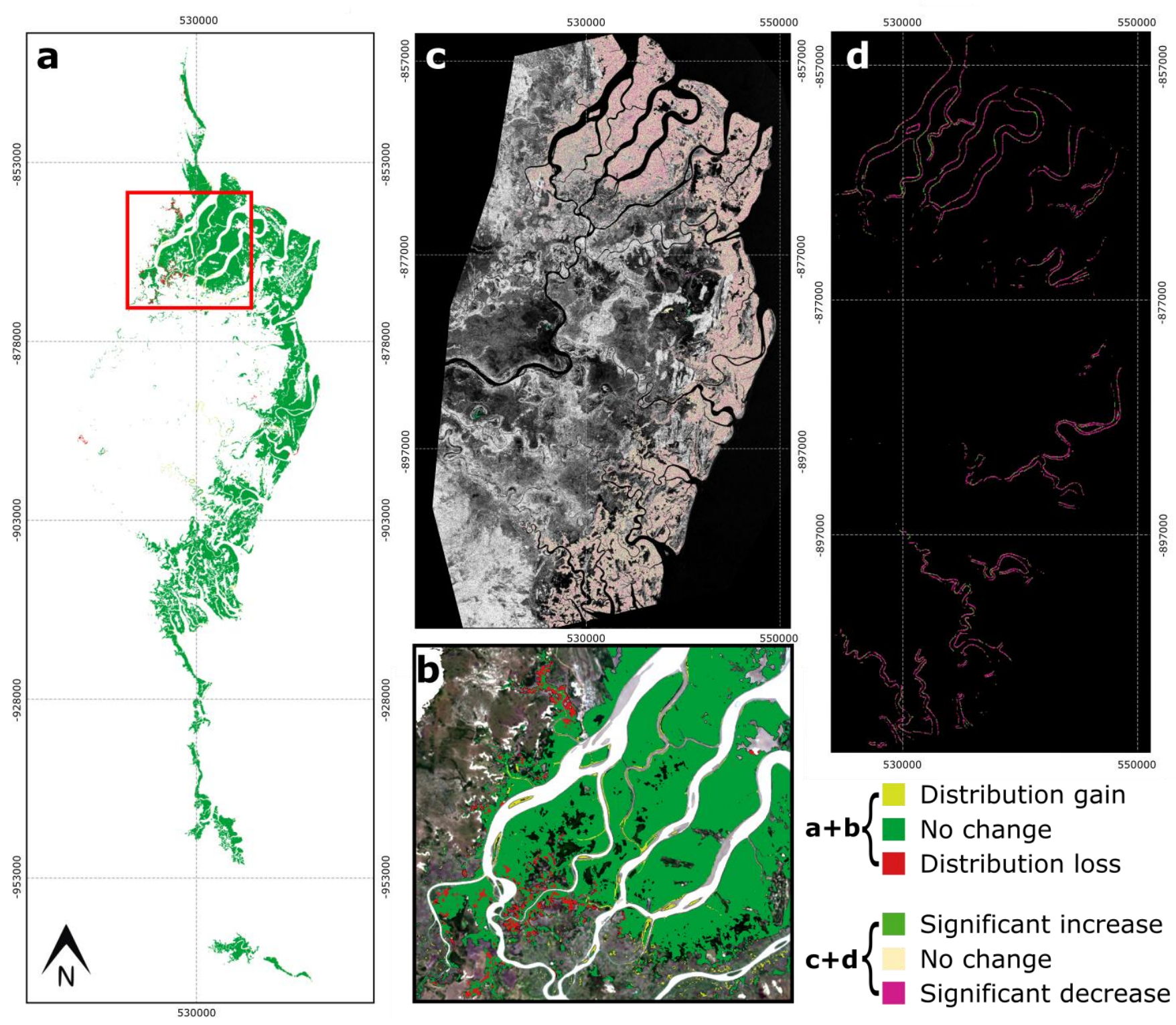


\begin{tabular}{|c|c|c|c|c|c|}
\hline Site & Capacity for resilience & $\begin{array}{c}\text { Capacity for } \\
\text { resistance }\end{array}$ & $\begin{array}{c}\text { Migration } \\
\text { availability } \\
\text { (topographic; } \\
\% \text { [radians]) }\end{array}$ & $\begin{array}{c}\text { Potential } \\
\text { change } \\
\text { (anthropogenic; } \\
\%)\end{array}$ & $\begin{array}{c}\text { Potential } \\
\text { change } \\
\text { (sediment; } \\
\text { tauTSM) }\end{array}$ \\
\hline $\begin{array}{l}\text { Saloum Delta, } \\
\text { SN }\end{array}$ & $\begin{array}{c}\text { Stable area } \\
(-0.09 \%) \\
\text { Landward migration } \\
<\text { Seaward loss } \\
(0.00 \% \mathrm{~L} ;-2.81 \% \mathrm{~S})\end{array}$ & $\begin{array}{c}\text { Marginal } \\
\text { biomass loss } \\
(-2.04 \%)\end{array}$ & $\begin{array}{c}82.92 \\
(\theta=0.098)\end{array}$ & -4.07 & -0.02 \\
\hline $\begin{array}{l}\text { Sherbro Bay, } \\
\text { SL }\end{array}$ & $\begin{array}{c}\text { Decreasing area } \\
(-2.46 \%) \\
\text { Landward migration } \\
\approx \text { Seaward loss } \\
(0.00 \% \mathrm{~L} ;-0.60 \% \mathrm{~S})\end{array}$ & $\begin{array}{l}\text { Stable biomass } \\
(-0.62 \%)\end{array}$ & $\begin{array}{c}63.07 \\
(\theta=0.123)\end{array}$ & 3.09 & 0.006 \\
\hline $\begin{array}{l}\text { Save River } \\
\text { Delta, } \\
\text { MZ }\end{array}$ & $\begin{array}{c}\text { Increasing area } \\
(4.55 \%) \\
\text { Landward migration } \\
>\text { Seaward loss } \\
(20.98 \% \mathrm{~L} ;-5.54 \% \mathrm{~S})\end{array}$ & $\begin{array}{c}\text { Biomass loss } \\
(-5.33 \%)\end{array}$ & $\begin{array}{c}93.82 \\
(\theta=0.064)\end{array}$ & 0.015 & - \\
\hline $\begin{array}{l}\text { Ruvuma } \\
\text { Estuary, } \\
\text { TZ }\end{array}$ & $\begin{array}{c}\text { Stable area } \\
(0.64 \%) \\
\text { Landward migration } \\
>\text { Seaward loss } \\
(6.54 \% \mathrm{~L} ;-5.57 \% \mathrm{~S})\end{array}$ & $\begin{array}{c}\text { Marginal } \\
\text { biomass loss } \\
(-3.96 \%)\end{array}$ & $\begin{array}{c}87.22 \\
(\theta=0.066)\end{array}$ & 0.38 & - \\
\hline $\begin{array}{l}\text { Rufiji Delta, } \\
\text { TZ }\end{array}$ & $\begin{array}{c}\text { Stable area } \\
(0.36 \%) \\
\text { Landward migration } \\
<\text { Seaward loss } \\
(1.85 \% \mathrm{~L} ;-5.62 \% \mathrm{~S})\end{array}$ & $\begin{array}{c}\text { Biomass loss } \\
(-5.34 \%)\end{array}$ & $\begin{array}{c}47.18 \\
(\theta=0.086)\end{array}$ & 6.34 & -0.04 \\
\hline $\begin{array}{l}\text { Mahajamba, } \\
\text { MG }\end{array}$ & $\begin{array}{c}\text { Increasing area } \\
(12.09 \%) \\
\text { Landward \& } \\
\text { Seaward increasing } \\
(31.11 \% \text { L; } 3.13 \% \mathrm{~S})\end{array}$ & $\begin{array}{c}\text { Biomass gain } \\
(1.56 \%)\end{array}$ & $\begin{array}{c}94.12 \\
(\theta=0.082)\end{array}$ & 0.00 & -0.005 \\
\hline $\begin{array}{l}\text { Sundarbans, } \\
\text { IN \& BD }\end{array}$ & $\begin{array}{c}\text { Stable area } \\
(0.21 \%) \\
\text { Landward migration } \\
>\text { Seaward loss } \\
(11.49 \% \mathrm{~L} ;-4.48 \% \mathrm{~S})\end{array}$ & $\begin{array}{l}\text { Stable biomass } \\
\quad(-0.66 \%)\end{array}$ & $\begin{array}{c}89.94 \\
(\theta=0.066)\end{array}$ & 0.13 & -0.004 \\
\hline
\end{tabular}

